\title{
Computational analysis of homogeneous nucleation and droplet growth applied to natural gas separators
}

\section{Análisis computacional de la nucleación homogénea y crecimiento de gotas aplicado a separadores de gas natural}

\author{
Natalia Prieto-Jiménez ${ }^{1}$, José Fuentes ${ }^{2}$, Germán González-Silva ${ }^{3}$ \\ ${ }^{1}$ Grupo de Investigación en Energía y Medio Ambiente (GIEMA), Universidad Industrial de Santander, Colombia. \\ Email: natispj@gmail.com. Orcid: 0000-0001-9178-7758. \\ ${ }^{2}$ Centro de Desarrollo Tecnológico-CDT del Gas, Colombia. Email: jfuentes@cdtdegas.com. \\ ${ }^{3}$ Grupo de Modelamiento de Procesos de Hidrocarburos, Universidad Industrial de Santander, Colombia. \\ Email: germangs@uis.edu.co. Orcid: 0000-0002-4642-1092.
}

Received: 27 November 2020. Accepted: 16 June 2021. Final version: 21 October 2021.

\begin{abstract}
A natural gas droplet is generated at certain thermodynamic conditions through three stages: supersaturation, where the gas has more molecules than it should have in equilibrium, forming "embryos" of liquid phase; nucleation, where embryos form groups of different shapes and sizes of nanometer order; and the droplet growth, where the number of molecules increases until equilibrium is reached. In this paper, the homogeneous nucleation and droplet growth of natural gas applied to gravitational separators operating at high pressure conditions (7MPa) are analyzed. The results showed that at a high pressure, the initial drop size reached was 8.024 nanometers and the final diameter of the drop was 4.18 micrometers.
\end{abstract}

Keywords: nucleation; droplet growth; molecular simulation; umbrella sampling.

\section{Resumen}

Una gota de condensado de gas natural se genera a ciertas condiciones termodinámicas a través de tres etapas: sobresaturación, donde el gas tiene más moléculas de las que debería tener en equilibrio, formando "embriones" de fase líquida; nucleación, donde los embriones forman grupos de diferentes formas y tamaños de orden de nanómetros; y el crecimiento de gota, donde el número de moléculas aumenta hasta alcanzar el equilibrio. En este artículo, se analizan la nucleación homogénea y el crecimiento de una gota de gas natural aplicado a separadores gravitacionales operando a condiciones de alta presión (7 MPa). Los resultados mostraron que, a alta presión, el tamaño de gota inicial alcanzado fue de 8,024 nanómetros y el diámetro final de la gota fue de 4,18 micrómetros.

Palabras clave: nucleación; crecimiento de gota; simulación molecular; muestreo sombrilla.

ISSN Printed: 1657 - 4583, ISSN Online: 2145 - 8456, CC BY-ND 4.0 (c) (1)

How to cite: N. Prieto-Jiménez, J. Fuentes, G. González-Silva, "Computational analysis of homogeneous nucleation and droplet growth applied to natural gas separators," Rev. UIS Ing., vol. 21, no. 1, pp. 83-94, 2022, doi: https://doi.org/10.18273/revuin.v21n1-2022007. 


\section{Introduction}

It is considered that natural gas is an essential source of fossil energy for different economic sectors. For instance, in the electrical sector, natural gas is an attractive option for new plants of generation due to its efficiency and the fact that it burns cleaner than coal or liquid derivatives of petroleum [1].

However, natural gas must satisfy specific quality standards regulated for each country before it is used in the industry and transportation sectors, or in residential use. Quality standards are accomplished through pretreatment of natural gas, where long chain liquid hydrocarbons are removed, to avoid deposition and gas condensation during the pipeline transport. Additionally, inorganic compounds such as carbon dioxide $\left(\mathrm{CO}_{2}\right)$, hydrogen sulfide $\left(\mathrm{H}_{2} \mathrm{~S}\right)$, nitrogen $\left(\mathrm{N}_{2}\right)$, water $\left(\mathrm{H}_{2} \mathrm{O}\right)$ and other impurities are removed or reduced; these compounds are responsible for operational problems, among which stand out corrosion in pipes, gas acidification hydrates formation, and particles deposition [2]. In the conventional process of natural gas phases, primary separation is carried out at operating pressures close to atmospheric [3], [4], [5]. Later, the treated gas is recompressed for its entry into the transport network, generating high operating costs.

High-pressure natural gas phases separation is an attractive alternative to reduce the costs associated with the recompression generated by conventional fossil fuel treatment [6], [7]. However, increasing the operating pressure decreases the density difference between the components of the liquid and gas phases, and the surface tension, which decreases the diameter of the condensate droplets, and, consequently, the separation process is more difficult, or in some cases, impossible to separate.

Several decades ago, numerical simulation has been used to study challenging phenomena in engineering processes. This technique allows to confirm, refute, or update conventional designs that were highly dependent on field experience or empirical correlations. Computational Fluid Dynamics (CFD) combines mathematical models and discretization methods to perform academic and industrial research [6], [8], [9], [10], [11], [12]. In the case of gas-liquid gravitational separation, there are three important physical principles: first, the momentum, where a change in the direction of the flow occurs just after the inlet nozzle in order to calm it down and perform the thick separation of the phases; second, sedimentation by gravity allows liquid droplets to settle to the bottom, and gas to rise to the top of the separator; and third, coalescence (Figure 1).
To understand the effect of coalescence on the phase separation process of natural gas at high pressure, it is necessary to know the mechanisms of birth and formation of each liquid droplet.

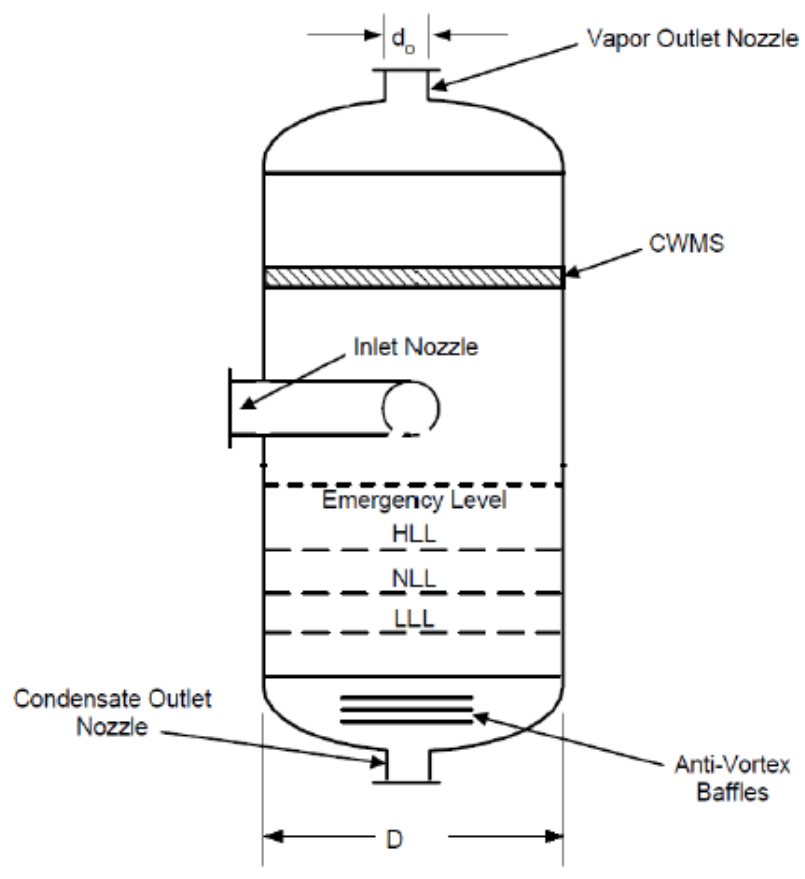

Figure 1. Schematic diagram of a vertical gravitational separator [13]. Where CWMS is the wire mesh demister, HLL is the High Liquid Level, NLL is the Normal Liquid Level and LLL is Low Liquid Level.

The formation of a droplet to certain thermodynamic conditions of pressure and temperature is generated from three key stages (Figure 2):

\subsection{Supersaturation}

It is defined as a meta-stable state of a gas-liquid mixture, where the gas would have more molecules per unit volume than it should have in equilibrium at those operating conditions. This meta-stable state generates a spontaneous formation (due to thermal fluctuations) of liquid phase "embryos" [14].

\subsection{Nucleation}

These embryos, resulting from the agglomeration of molecules, form clusters of different shapes and sizes of nanometers [15]. 


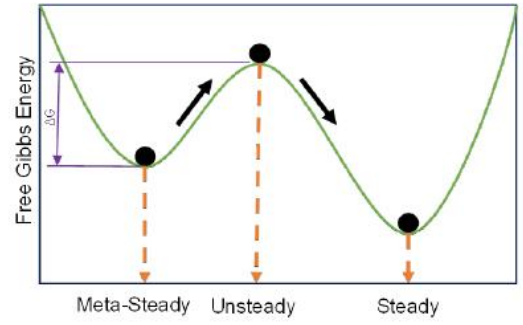

a)

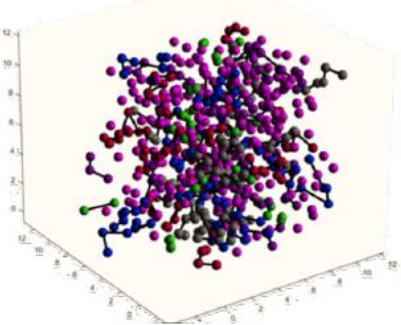

b)

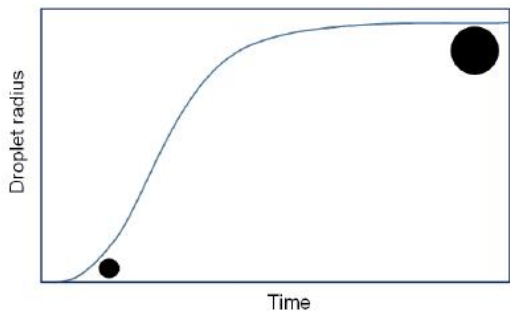

c)

Figure 2. Steps of natural gas droplet formation: a) Supersaturation b) Nucleation c) Droplet growth.

\subsection{Droplet growth}

Once the core is formed, the number of molecules increases and the droplet grows until reaching the thermodynamic equilibrium, going from a size of the order of nanometers to the order of micrometers [16]. Knudsen's number $(\mathrm{Kn})$, defined as the relationship between the free path of a vapor molecule (radius of motion) and the diameter of the drop determines the different regimes over which growth will occur. If $\mathrm{Kn}<1$ there is little movement freedom of molecules (high pressure) and diffusion controls growth, whereas if $\mathrm{Kn}>1$ there is more space available for the molecules' movement and kinetics controls growth [17].

It is possible to calculate the transition of molecules from the gas phase to liquid phase through four fundamental theories: First, "Classical Nucleation Theory (CNT)", developed initially by Lord Kelvin and Gibbs more than a century ago. It assumes that the formed cores are entirely spherical and that the associated properties are macroscopic. CNT works well for pure substances and low molecules numbers [18]. The most important research works on the CNT are those of Katz and Wiedersich [19], Girshick and Chiu [20] and Wilemski [21]. The Second theory is the "Semi-Phenomenological Theory (SPT)" that utilizes statistical thermodynamics for the calculation of properties [22]. Kalikmanov et al. [14] used this theory in natural gas separation with unsatisfactory results. The third theory is the "Functional Density Theory (FDT)", which considers the drop as an inhomogeneous fluid with a density profile that varies from the drop center to a distant point in the gas phase [23]. The most recent is based on "Molecular Simulation (MS)", where the interactions between atoms or molecules are analyzed using potential models that determine the interactions using methods such as Monte Carlo or molecular dynamics [24]. The MS procedure was the one used in this article.

\section{Mathematical model}

\subsection{Supersaturation}

Potentially condensable molecules have a lower chemical potential in the liquid phase $\left(\mu^{l}\right)$ than in the gas (vapor) phase $\left(\mu^{v}\right)$. The condition for the gas phase to condense is shown in equation (1).

$$
\Delta \mu=\mu^{v}\left(p^{v}, T\right)-\mu^{l}\left(p^{v}, T\right)>0
$$

Where $p^{v}$ is the vapor pressure and $T$ is temperature. From equation (1), Kalikmanov [15] defines supersaturation as:

$$
S=\exp \left[\frac{\mu^{v}\left(p^{v}, T\right)-\mu^{s a t}(T)}{k_{B} T}\right]
$$

Where $k_{B}$ is the Boltzmann constant. For real gas cases, it is necessary to add a "widening coefficient" $f_{w}$, which corrects the non-ideality of the gaseous system (equation $3)$.

$$
S=\frac{y_{v} p}{f_{w}(p, T) p^{s a t}(T)}
$$

Where $y_{v}$ corresponds to the molar fraction of the component within analyzed mixture.

\subsection{Nucleation}

Final drop size depends on the number and size of formed cores within the system, which in turn depends on the thermodynamic conditions and chemical characteristics of condensed species. 
To bring the system from a meta-stable to a stable state, it is necessary to overcome an energy barrier $G$, which includes the energy necessary for the phase change plus the formation energy of the gas-liquid interface [25], as follows:

$$
G=E_{\text {liquid }}+E_{\text {surface tension }}
$$

Where $E_{\text {liquid }}$ and $E_{\text {surface tension }}$ are the energies related to the liquid and the surface tensión, respectively. The distribution of the cluster when the system has reached equilibrium $\rho_{e q}$, is given by:

$$
\rho_{e q}(n)=\rho_{1} \exp \left[\frac{-\Delta G(n)}{k_{B} T}\right]
$$

Where $\rho_{1}$ is a temperature dependent constant. The challenge of all nucleation studies is the energy barrier estimation $(\Delta G)$, the difference in calculation accuracy depends on the theory used.

\subsubsection{Signal netics and nucleation rate}

Becker [26] presented the following general equation to simulate the nucleation rate:

$$
\frac{d \rho(n, t)}{d t}=\sum_{j} n_{j} V_{j \rightarrow i}-\sum_{i} n_{i} V_{i \rightarrow j}
$$

Where $V_{j \rightarrow i}$ represents the velocity at which the cluster $j$ becomes the cluster $i$ (evaporation or condensation).

\subsubsection{Molecular simulation}

Meso-scale analysis can be done through molecular dynamics (MD) or Monte Carlo simulation (MCS). The statistical ensamble used here were the NPT (Number of molecules, Pressure and Temperature constants) and the Gibbs collective [27]. In the NPT ensamble, volume and system total energy vary for each state, therefore, the probability of a state occurring is a function of the total energy $E_{j}$ and the system volume $V_{j}$ (equation 7)

$$
p_{j}=\frac{\exp \left[-\beta\left(E_{j}-P V_{j}\right)\right]}{Q_{N P T}}
$$

Where $\beta=\frac{1}{k_{B} T}$ is the Boltzmann factor [28] $Q_{N P T}$ is the collective partition function. The potential energy $U$ is divided into an intramolecular and an intermolecular component:

$$
U=U_{\text {intra }}+U_{\text {inter }}
$$

In turn, intramolecular energy is divided into local and non-local contributions.

$$
U_{\text {intra }}=U_{\text {local }}+U_{\text {nonlocal }}
$$

Local contributions define the molecular structure at the atomic level and determine the bond distance between atoms, bond angle, and atom torsion using the following expression:

$$
\begin{aligned}
U_{\text {local }}=\sum_{l} \frac{1}{2} k_{l}(l & \left.-l_{0}\right)^{2} \\
& +\sum_{\theta} \frac{1}{2} k_{\theta}\left(\theta-\theta_{0}\right)^{2} \\
& +\sum_{c} \sum_{i=0}^{5} a_{i} \cos (\varphi)^{i}
\end{aligned}
$$

Where $k_{l}$ represents the constant of force; $l$, temporary distance between atoms, $l_{0}$ a distance in equilibrium, $\theta$ the angle formed by three atoms, $\theta_{0}$ the equilibrium value, $\varphi$ the torsional rotation angle, and $a_{i}$ are torsional constants. Non-local contributions correspond to the intramolecular interactions between atoms or monomers separated from each other by the bonds. The usual approach is shown in equation (11).

$$
U_{\text {nonlocal }}=\frac{1}{2} \sum_{i=1}^{n} \sum_{j \in \tau(i)} u_{d i s}(i j)
$$

The second sum is the set of atoms $\tau(i)$ that presents the interactions of non-local type with the atom $i$. The factor $\frac{1}{2}$ is applied to avoid duplicate interactions, and $u_{d i s}$ is a dispersion forces potential that depends on the distances between centers of atoms $i$ and $j$. It is common to use Lennard-Jones potential $\left(u_{L J}\right)$ to characterize dispersed forces potential:

$$
u_{L J}=4 \varepsilon_{i j}\left[\left(\frac{\sigma_{i j}}{r_{i j}}\right)^{12}-\left(\frac{\sigma_{i j}}{r_{i j}}\right)^{6}\right]
$$

Where $\sigma_{i j}$ is a bond parameter (atoms diameter), $\varepsilon_{i j}$ is an energetic parameter, and $r_{i j}$ represents the separation between two atoms. Interaction parameters were calculated using the Lorentz-Berthelot mixing rule. The intermolecular energy was estimated by molecular pairs approximation and equation (13). 


$$
U_{\text {inter }}\left(r_{i j}\right)=\sum_{k=1}^{n} \sum_{l=1}^{n} u_{d i s}(k l)
$$

To reduce the computational cost when there are long chain alkanes, the united atom models were used (TraPPEUA - Transferable Potentials for Phase Equilibria-United Atom) [29].

\subsubsection{Gibbs Free Energy}

Kalikmanov [15] defines the probability distribution function of core formation as follows:

$$
\langle P(n)\rangle=\exp \left(-\beta \Delta G_{n}\right)
$$

MCS alone does not adequately predict the size of the cluster. Therefore, the umbrella sampling method was used, which consists of adding a fictitious term to the energy of the system (as a bias) that allows more efficient sampling along the system coordinates [30]. The method is applied in several simulations called windows. The fictitious potential $w_{i}$ corresponding to the window $i$ depends on the core size.

$$
E(r)^{b}=E(r)^{u}+w_{i}(n)
$$

Where $E(r)^{b}$ (superscript $b$ indicates a variable with bias) is the system energy with potential for bias $w_{i}(n)$, while $E(r)^{u}$ represents the energy without the potential for bias. Using the umbrella sampling, the probability distribution of cores formation can be expressed according to equation (16).

$$
P(n)_{i}^{u}=\frac{P(n)_{i}^{b} \exp \left[-\beta w_{i}(n)\right]}{\left\langle\exp \left[-\beta w_{i}(n)\right]\right\rangle}
$$

Where $P(n)_{i}^{u}$ is the core formation probability distribution of size $n$ without bias potential and $P(n)_{i}^{b}$ is the probability distribution obtained by adding the potential for bias. This potential can vary in each window; therefore, it is possible to evaluate different cluster sizes within the expected sizes range. Finally, a harmonic bias was used, as observed in equation (17).

$$
w_{i}(n)=\frac{k}{2}\left(n-n_{r e f}\right)^{2}
$$

Where $n_{r e f}$ is the molecules number in the reference core and $k$ is the harmonic function constant. The umbrella integration method estimates the probable drop sizes and the probability of droplet formation, obtained as the weighted average of individual probabilities of each window, as follows:

$$
\begin{gathered}
P(n)^{u}=\sum_{i}^{\text {window }} P(n)_{i} P(n)_{i}^{u} \\
P(n)_{i}=\frac{a(n)_{i}}{\sum_{j} a(n)_{j}} \\
a(n)_{i}=N_{i} P(n)_{i}^{b}
\end{gathered}
$$

\subsection{Droplet growth}

The two most commonly used models for droplet growth are the Young model [31] and the Gyarmathy model [32], the difference lies in the regime over which each of them develops. The Knudsen number $(\mathrm{Kn})$ determines the regime. Young's model is used in the continuous or diffusion regime $(0 \leq K n \leq 0.1)$, whereas the Gyarmathy model is used in the transition regime, $(0.1 \leq K n \leq 10)$. This research was done in the application range of the Young model.

Mass and energy balance equations of the Young model are shown in equations (21) and (22) respectively [31].

$$
\begin{gathered}
\dot{M}=4 \pi r_{d}^{2}\left(\frac{\rho_{v s} R_{v} T_{d}}{\sqrt{2 \pi R_{v} T_{d}}}-\frac{\rho_{v i} R_{v} T_{i}}{\sqrt{2 \pi R_{v} T_{i}}}\right) \\
\dot{E}=4 \pi r_{d}^{2}\left[\frac{\rho_{v i} R_{v} T_{i}\left(C_{p v}-\frac{R_{v}}{2}\right)}{\sqrt{2 \pi R_{v} T_{i}}}\right. \\
\left.-\frac{\rho_{g i} R_{g} T_{i}\left(C_{p g}-\frac{R_{g}}{2}\right)}{\sqrt{2 \pi R_{g} T_{i}}}\right]\left(T_{d}\right. \\
\left.-T_{i}\right)+\frac{r_{d}^{2}}{2 r_{i}^{2}} \dot{Q}_{c i}+\dot{M} C_{p v} T_{d} \\
-\dot{M} \frac{R_{v}}{2} T_{d}\left(1-\frac{r_{d}^{2}}{2 r_{i}^{2}}\right) \\
-\frac{r_{d}^{2}}{2 r_{i}^{2}} \dot{M} C_{p v}\left(T_{d}-T_{i}\right)
\end{gathered}
$$

Where $\dot{Q}_{c i}=\dot{Q}_{v i}+\dot{Q}_{g i}=4 \pi r_{i} k_{m}\left(T_{i}-T_{\infty}\right) ; R_{v}$ and $R_{g}$ are specific constants of vapor and gas respectively; $C_{p v}$ and $C_{p g}$ are the heat capacities of each of phases. 
$r_{i}=r_{d}(1+2 \beta K n)$, where $\beta$ is an experimental coeffcient (0.75), and $\lambda$ (of $K n$ ) the average molecular free distance. $T_{d}$ and $r_{d}$ are variables related to the liquid.

\subsection{Porous Media Model}

Porous Media Model (PMM) introduces source terms to the transport equations of the multiphase model [33]. The source term added to the momentum equation is divided into two terms: viscous loss and inertial loss.

$$
S_{i}=-\left(\sum_{j=1}^{3} D_{i j} \mu V_{j}+\sum_{j=1}^{3} C_{i j} \frac{1}{2} \rho|V| V_{j}\right)
$$

Where $S_{i}$ is the source term for the $\mathrm{i}^{\text {th }}$ momentum equation; $\mu$ is the viscosity, $\rho$ is the density, $|V|$ the velocity magnitude; $D$ and $C$ are pre-established matrices. Equation (23) contributes to the pressure gradiente in the porous control volume proportionally to the fluid velocity. For the case of homogeneous PMM, equation (23) is reduced to equation (24)

$$
S_{i}=-\left(\frac{\mu}{\alpha} V_{j}+C_{2} \frac{1}{2} \rho|V| V_{i}\right)
$$

Where $\alpha$ is the permeability factor and $C_{2}$ is the inertial resistance factor.

The PMM model is a strategy that Ansys-Fluent CFD simulator uses to represent the behavior of a wire mesh demister; in this way it is possible to know the amount of liquid droplets that are trapped in the equipment.

\section{Numerical simulation}

Table 1 shows the gas composition and operating conditions of the separation system. A maximum of 1000 molecules was used for the nucleation and droplet growth analysis.

A Matlab ${ }^{\text {TM }}$ code was created to develop the models that characterize the behavior of the mixture using the NPT and Gibbs ensembles. Total energy was estimated using the Lennard-Jones potential and the TraPPEUA method for the computational effort reduction. The MCS included three movements associated with the methodology of configurational bias: Translation, volume change, and molecules transfer. The windows used in the umbrella sampling were five: $5,15,25,35$, and 100 respectively. The Matlab code also included the Young model for droplet growth.
Table 1. Natural gas mixture characterization and system operating conditions

\begin{tabular}{|c|c|}
\hline Component & Mole fraction \\
\hline $\mathrm{CH}_{4}$ & 0.936 \\
\hline $\mathrm{C}_{2} H_{6}$ & 0.0263 \\
\hline$n C_{4} H_{10}$ & 0.0149 \\
\hline$i C_{4} H_{10}$ & 0.0149 \\
\hline$n C_{5} H_{12}$ & 0.0079 \\
\hline \multicolumn{2}{|c|}{ Operation Pressure } \\
$7 \mathrm{MPa}$ \\
\hline Operation Temperature \\
260 K \\
\hline \multicolumn{2}{|c|}{ Molar Flow } \\
1 MSCFD
\end{tabular}

\subsection{Geometry, Mesh and CFD conditions}

The droplet size at equilibrium was an input parameter for the CFD simulations of a vertical gravitational separator of $0.3 \mathrm{~m}$ in diameter and $1.55 \mathrm{~m}$ in length, equipped with a plate-type inlet device and a computational zone designated for the porous media (Figure 3).

Both for mesh tests and for phase separation analysis of natural gas; steady state simulations were developed with coupled discretization schemes using the second order Upwind for transport equations, in Fluent v18. Two Eulerian phases were assumed with the properties, models, initial and boundary conditions shown in Table 2. The wire mesh cell zone conditions were taken from Helsør and Svendsen, using the properties of the demister type D [34]. Therefore, the constants of the equation (24) are:

$$
\frac{1}{\alpha}=8.333 \times 10^{-6} \mathrm{~m}^{2} \quad C_{2}=92 \mathrm{~m}^{-1}
$$

\section{Results}

Initially, the organization of spherical molecules was carried out, and then the simulation to reach equilibrium. This equilibrium was reached at approximately 5000 cycles, with 1000 molecules (Figure 4). This system was compared with another that contained 100 molecules, disturbances were observed in the second system and therefore, it did not reach equilibrium. 

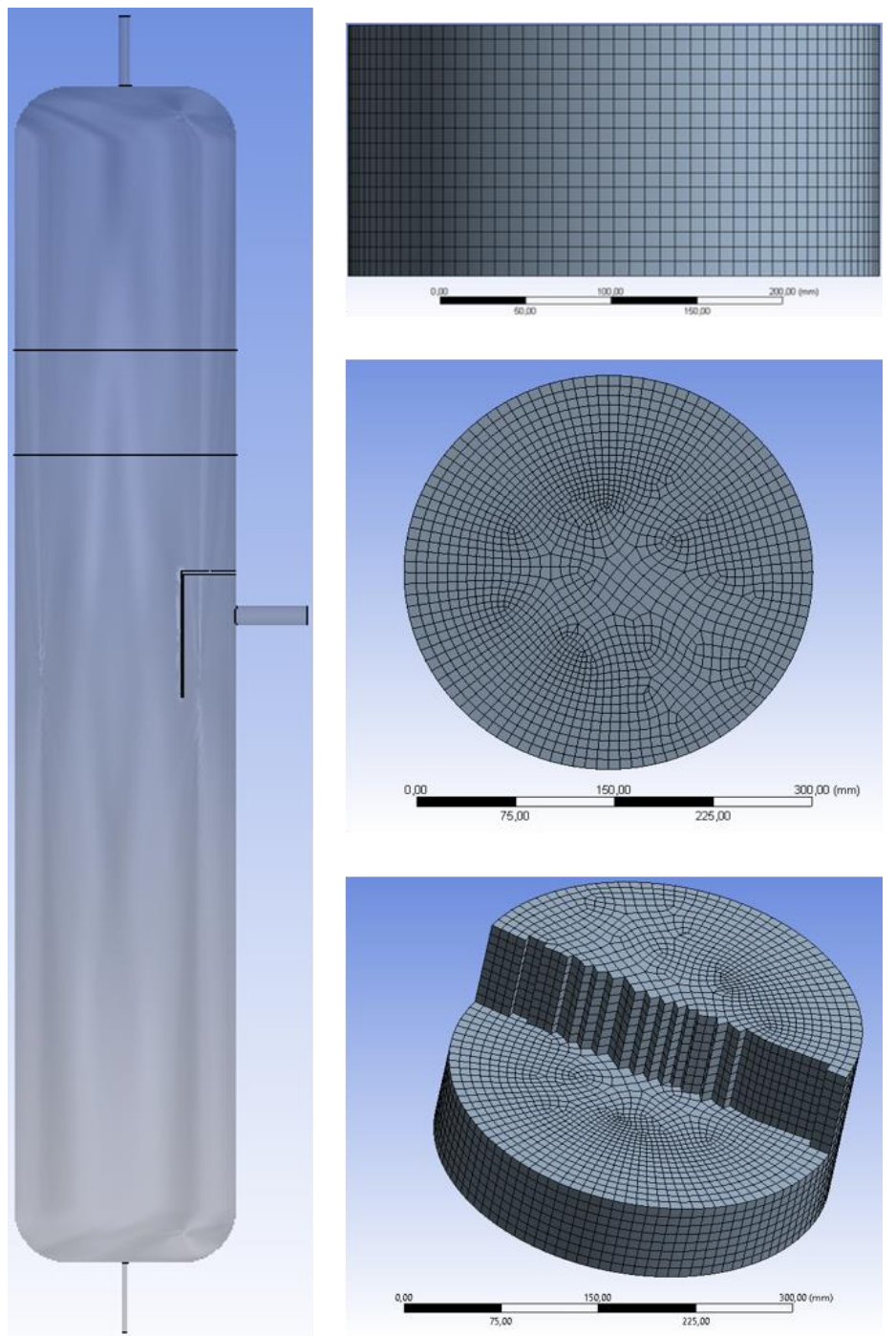

Figure 3. Geometry and mesh for numerical simulations in CFD, showing three different mesh section: at the liquid outlet, at the mix inlet section, and at the demister.

Table 2. Properties of Eulerian-phases, initial an boundary conditions for CFD simulation

\begin{tabular}{|l|c|c|}
\hline \multicolumn{3}{|c|}{ Eulerian-phases properties } \\
\hline & Gas phase & Liquid phase \\
\hline Density kg/m ${ }^{3}$ & 61.09 & 527.3 \\
\hline Viscosity kg/ms & $1.2 \times 10^{-5}$ & $1.4 \times 10^{-4}$ \\
\hline Mol. Weight kg/kmol & 17.51 & 43.39 \\
\hline Heat capacity J/kgK & 2991 & 2487 \\
\hline Th. conduc. W/mK & 0.03474 & 0.09184 \\
\hline Eq. of state & real SRK & -- \\
\hline Turbulence & \multicolumn{2}{|c|}{$\mathrm{k}-\omega \mathrm{SST}$} \\
\hline \multicolumn{3}{|c|}{ Initial and boundary conditions } \\
\hline Inlet Velocity: $7.5 \mathrm{~m} / \mathrm{s}$ \\
\hline Outlet & \multicolumn{2}{|c|}{ Pressure } \\
\hline Wall & \multicolumn{2}{|c|}{ No-slip condition } \\
\hline
\end{tabular}


Figure 4 shows the position of the molecules before and after reaching equilibrium. A total of 5000 cycles were sufficient for the system to reach equilibrium at the pressure and temperature established in Table 1.

\subsection{Gibbs free energy}

Each of the 5 windows used in the umbrella sampling required 1000 cycles, varying the reference core size from 5 to 100. The largest core size found for this system was 36 molecules. The calculation of the nondimensional Gibbs free energy barrier $(-\beta \Delta G)$ made by the umbrella integration is shown in the Figures 5 and 6. The colors are: $\mathrm{CH}_{4}$ pink, $\mathrm{C}_{2} \mathrm{H}_{6}$ green, $\mathrm{nC}_{4} \mathrm{H}_{10}$ red, $i \mathrm{C}_{4} \mathrm{H}_{10}$ grey and $n \mathrm{C}_{5} \mathrm{H}_{12}$ blue.

\subsection{Droplet growth}

Calculations by molecular simulation produced an initial droplet radius of 8.054 nanometers. This value is the input parameter for the estimation of the droplet growth curve by Young model. The simulations in Matlab showed the growth profile of the Figure 7.

The equilibrium was reached at 50 microseconds. At $t=$ 0 the droplet radius was the obtained by the nucleation process.

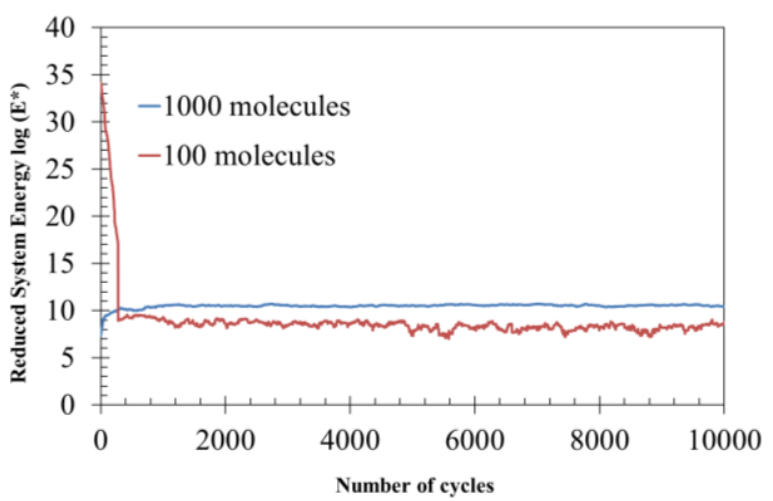

Figure 4. Equilibrium curve for 100 and 1000 molecules.

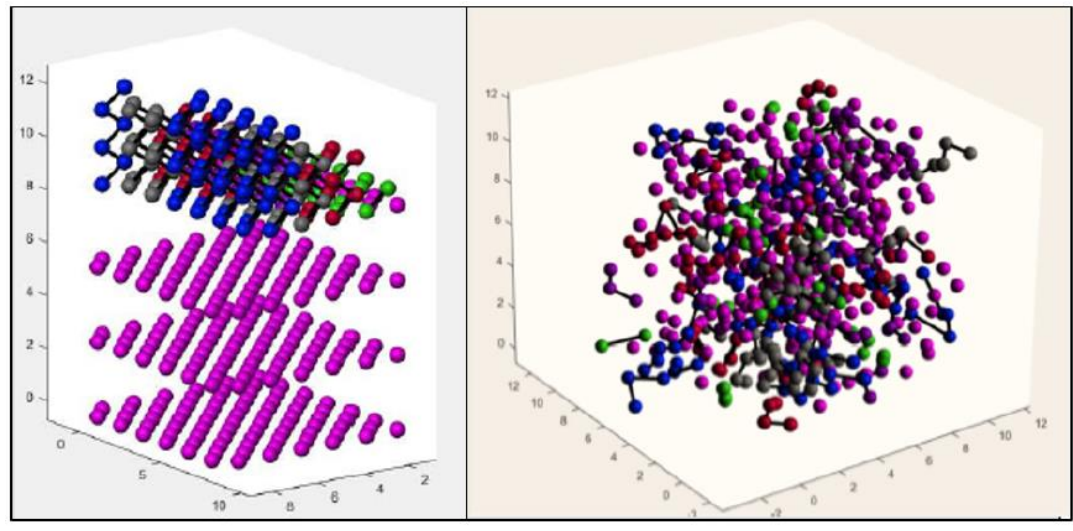

Before

After

Figure 5. Graphical representation (reduced length units) of the molecules location before and after reaching equilibrium.

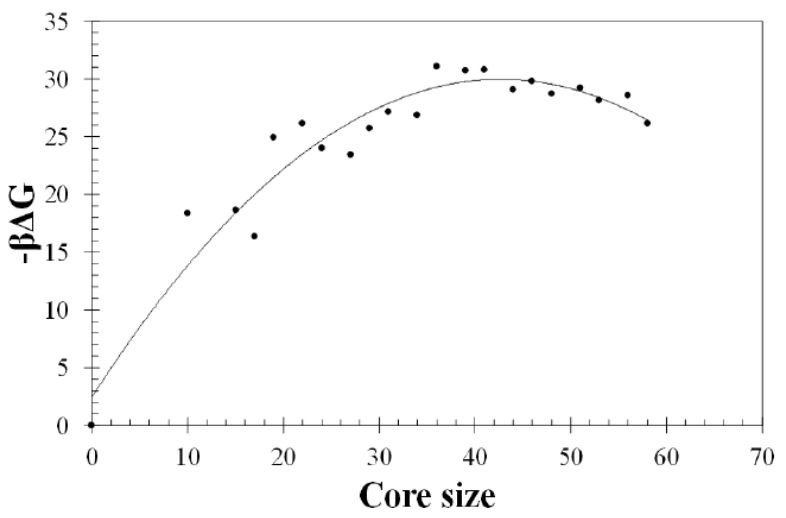

Figure 6. Gibbs free energy barrier as a function of core size (in nanometers). 
The final droplet size was reached when the radius remained stable with time. The result was a radius of 2.09 micrometers.

\subsection{Porous media model}

The final stage of this analysis corresponds to CFD simulation of a wire mesh type demister by assuming that it has a porous medium behavior within the gravitational separator.

The Eulerian approach was used for both the primary phase (gas) and the secondary phase (droplets). A constant drop size was assumed and equivalent to that obtained in section 4.2. A mesh independence test showed that a geometry with 1,451,217 control volumes was sufficient to obtain a balance between numerical precision and computational effort.

Figure 8 shows the results obtained for pressure drop, velocity and liquid volumetric fraction fields inside the separator. It is possible to observe that the porous medium generates a pressure gradient that is proportional to the velocity of the fluid and has a value of $1.8 \mathrm{kPa}$ (Figure 8a). The velocity field contour in Figure $8 \mathrm{~b}$ shows that in general there are adequate conditions for phase separation because the velocity within the separator was below the terminal velocity, according to the settling theory (equations 25 and 26).

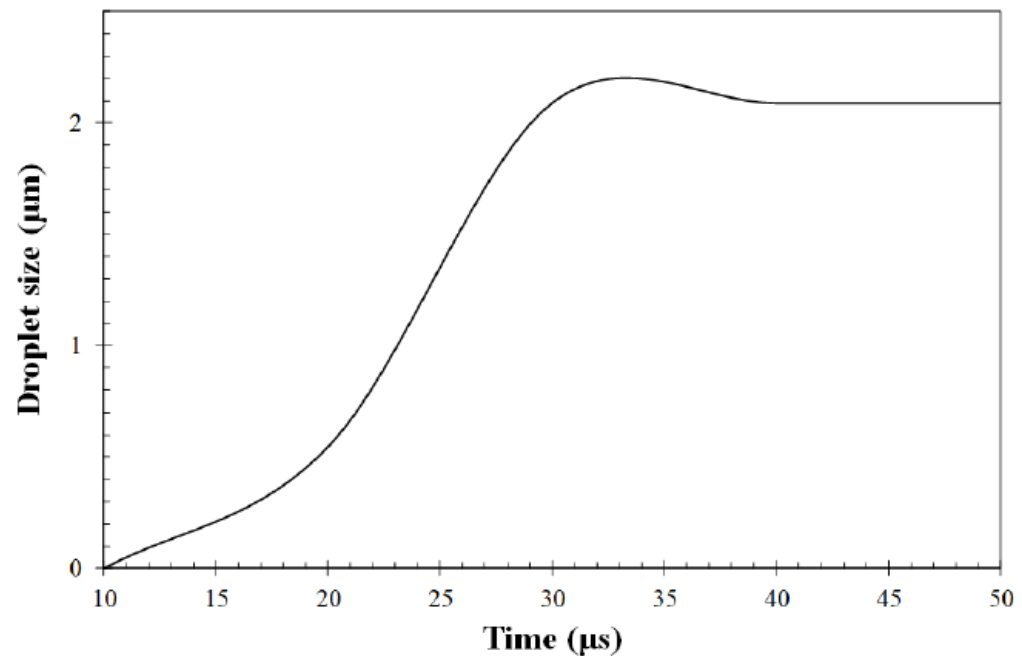

Figure 7. Droplet growth profile using Young model.

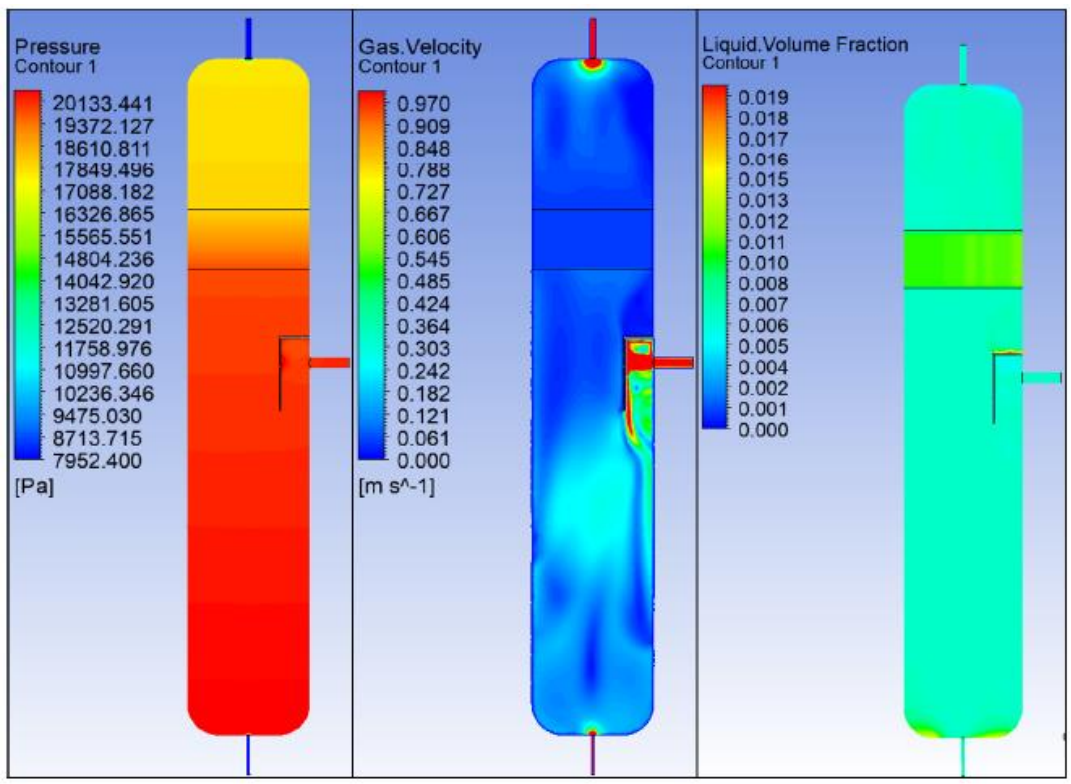

Figure 8. Contours of (a) pressure drop, (b) velocity and (c) liquid volumetric fraction fields in Ansys Fluent. 


$$
\begin{gathered}
U_{T}=\sqrt{\frac{4 g D_{p}\left(\rho_{l}-\rho_{v}\right)}{3 C_{D} \rho_{v}}}=K \sqrt{\frac{\rho_{l}-\rho_{v}}{\rho_{v}}} \\
=0.23 \frac{\mathrm{m}}{\mathrm{s}} \\
K=\sqrt{\frac{4 g D_{p}}{3 C_{D}}}
\end{gathered}
$$

Where $D_{p}$ is the particle diameter, $g$ gravity force, $C_{D}$ drag coefficient, $\rho_{l}$, and $\rho_{v}$ are the density of liquid phase and vapor phase respectively, and $K$ is an empirical constant developed by Souders [35]. Finally, Figure 8c shows the liquid volumetric fraction contour. It is notorious that for a droplet size of 2.09 micrometers at 7 $\mathrm{MPa}$ of operating pressure, there is a high percentage of entrainment, so it is necessary to refine the CFD models used for the demister.

\section{Conclusion}

The analysis of gas-liquid mixture droplet formation and growth was carried out using molecular simulation techniques, Monte Carlo movements, and umbrella sampling to speed up the simulations convergence in Matlab.

A Thirty-six molecules core was formed, with a radius of 8.054 nanometers. Subsequently the droplet growth curve was constructed, observing a final radius of 2.09 micrometers that agrees with what was expected for the high-pressure condition.

There were improvements in the calculation of the initial drop size of natural gas, in comparison with the classical nucleation theory. Nevertheless, some properties such as surface tension still were calculated with macroscopic models.

This estimation of the drop size serves as a precedent for the numerical simulation (with CFD) of the high-pressure gravitational phase separation processes, which are presented as a potential alternative to eliminate or reduce the energy expenditure of re-compression in natural gas treatment plants.

\section{Acknowledgements}

The authors would like to thank the Universidad Industrial de Santander for the academic support, and Minciencias for the financial support.

\section{References}

[1] British Petroleum, "BP Statistical Review of World Energy 2017," Br. Pet., vol. 66, pp. 1-52, 2017 [Online]. Available:

https://www.connaissancedesenergies.org/sites/default/f iles/pdf-actualites/bp-statistical-review-of-world-

energy-2017-full-report.pdf.

[2] A. Bahadori, Natural gas processing: technology and engineering design. Waltham, MA, USA: Gulf Professional Publishing, 2014.

[3] M. Stewart, K. Arnold, "Two-Phase Gas-Liquid Separators," in Gas-Liquid And Liquid-Liquid Separators, New Jersey, NJ, USA: Gulf Professional Publishing, 2008, pp. 65-130.

[4] G. Gonzalez-Silva, J. Botett-Cervantes, and N. Prieto-Jiménez, "Predicción del equilibrio vapor-líquido de la mezcla acetato de etilo-etanol usando la ecuación de estado de Peng Robinson," Rev. UIS Ing., vol. 20, no. 1, pp. 135-142, 2020, doi: https://doi.org/10.18273/revuin.v20n1-2021012.

[5] D. Moreno-Díaz, N. Prieto-Jiménez, G. GonzálezSilva, "Modelación del equilibrio líquido-vapor del sistema cloroformo-metano usando Van Laar y Peng Robinson," Inf. Técnico, vol. 83, no. 2, pp. 112-120, 2019, doi: https://doi.org/10.23850/22565035.2042.

[6] J. S. Cornejo Caceres, N. Prieto, G. Gonzalez, and A. Chaves-Guerrero, "Numerical Simulation of a Natural Gas Cylindrical Cyclone Separator Using Computational Fluid Dynamics," Ind. Eng. Chem. Res., vol. 58, no. 31, pp. 14323-14332, 2019, doi: https://doi.org/10.1021/acs.iecr.9b01217.

[7] N. Prieto Jiménez, "Simulação da combustão de coque em regeneradores FCC usando fluidodinâmica computacional," 2011, pp. 96 [Online]. Available: http://repositorio.unicamp.br/jspui/handle/REPOSIP/26 6866.

[8] G. González, N. Prieto, I. Mercado, "Large Eddy Simulation (LES) Aplicado a un lecho fluidizado gassólido. Parte I: Reactor a escala de laboratorio," Rev. UIS Ing., vol. 17, no. 1, pp. 93-104, 2018, doi: http://doi.org/10.18273/revuin.v17n1-2018009. 
[9] A. Ghaffarkhah, M. Ameri Shahrabi, M. Keshavarz Moraveji, H. Eslami, “Application of CFD for designing conventional three phase oilfield separator," Egypt. J. Pet., vol. 26, no. 2, pp. 413-420, 2017, doi: https://doi.org/10.1016/j.ejpe.2016.06.003.

[10]N. Kharoua, L. Khezzar, H. Saadawi, "CFD Modelling of a Horizontal Three-Phase Separator: A Population Balance Approach," Am. J. Fluid Dyn., vol. 3, no. 4, pp. 101-118, 2013, doi: https://doi.org/10.5923/j.ajfd.20130304.03.

[11]G. G. Silva, N. P. Jiménez, O. F. Salazar, "Fluid Dynamics of Gas-Solid Fluidized Beds," in Advanced Fluid Dynamics, Rijeka, Croatia, InTech, 2012, pp. 39.

[12]N. P. Jiménez, M. J. Hodapp, M. G. E. Silva, M. Mori, "Simulation of the coke combustion in a FCC regenerator using Computational Fluid Dynamics," in 4to Taller Latinoamericano de CFD Aplicado a la Industria del Petróleo y Gas, Rio de Janeiro, Brasil, 2010.

[13]ExxonMobil, "Chapter 5. Drums: Vapor-Liquid Separators.," in ExxonMobil Design Practices: ExxonMobil Research and Engineering Company, 1999.

[14] V. Kalikmanov, M. Betting, J. Bruining, D. M. Smeulders, "New developments in nucleation theory and their impact on natural gas separation," in Conferencia y Exposición Técnica Anual de la SPE, Anaheim, California, EE. UU, 2007, doi: https://doi.org/10.2118/110736-MS.

[15]V. I. Kalikmanov, "Classical nucleation theory," in Nucleation theory, Dordrecht: Springer, 2013, pp. 17-41, doi: https://doi.org/10.1007/978-90-481-3643-8_3.

[16]H. N. Pathak, "Nucleation and Droplet Growth During Co-condensation of Nonane and D $2 \mathrm{O}$ in a Supersonic Nozzle," Ph.D. dissertation, The Ohio State University, 2013.

[17]G. Lebon, D. Jou, J. Casas-Vázquez, Understanding non-equilibrium thermodynamics, vol. 295. Heidelberg, Germany: Springer, 2008.

[18]J. Merikanto et al., "Monte Carlo simulations of molecular clusters in nucleation," dissertation, University of Helsinki, 2007.
[19]J. L. Katz, H. Wiedersich, "Nucleation theory without Maxwell demons," J. Colloid Interface Sci., vol. 61, no. 2, pp. 351-355, 1977, doi: https://doi.org/10.1016/0021-9797(77)90397-6.

[20]S. L. Girshick, C. Chiu, "Kinetic nucleation theory: A new expression for the rate of homogeneous nucleation from an ideal supersaturated vapor," J. Chem. Phys., vol. 93, no. 2, pp. 1273-1277, 1990, doi: https://doi.org/10.1063/1.459191.

[21]G. Wilemski, "The Kelvin equation and selfconsistent nucleation theory," J. Chem. Phys., vol. 103, no. 3, pp. 1119-1126, 1995, doi: https://doi.org/10.1063/1.469822.

[22]V. I. Kalikmanov, J. Wölk, T. Kraska, "Argon nucleation: Bringing together theory, simulations, and experiment," J. Chem. Phys., vol. 128, no. 12, pp. 124506, 2008, doi: https://doi.org/10.1063/1.2888995.

[23]I. Napari, "Density functional theory of nucleation and phase behavior in binary fluid systems," in Finnish Association for Aerosol Research, Helsinki, no. 49, 2000, pp. 1-27.

[24]B. Chen, J. I. Siepmann, K. J. Oh, M. L. Klein, "Simulating vapor-liquid nucleation of n-alkanes," $J$. Chem. Phys., vol. 116, no. 10, pp. 4317-4329, 2002, doi: https://doi.org/10.1063/1.1445751.

[25]M. Santra, S. Chakrabarty, B. Bagchi, "Gas-liquid nucleation in a two dimensional system," J. Chem. Phys., vol. 129, no. 23, pp. 234704, 2008, doi: https://doi.org/10.1063/1.3037241.

[26]R. Becker and W. Döring, "The kinetic treatment of nuclear formation in supersaturated vapors," Ann. Phys. (N. Y)., vol. 24, pp. 719, 1935.

[27]A. Z. Panagiotopoulos, "Direct determination of phase coexistence properties of fluids by Monte Carlo simulation in a new ensemble," Mol. Phys., vol. 61, no. 4, pp. 813-826, 1987, doi: https://doi.org/10.1080/00268978700101491.

[28]R. W. Hakala, "A new derivation of the Boltzmann distribution law," J. Chem. Educ., vol. 38, no. 1, pp. 33, 1961. 
[29]B. Chen and J. I. Siepmann, "Improving the Efficiency of the Aggregation- Volume- Bias Monte Carlo Algorithm," J. Phys. Chem. B, vol. 105, no. 45, pp. 11275-11282, 2001, doi: https://doi.org/10.1021/jp012209k.

[30]K. Johannes, "Umbrella sampling," Wiley Interdiscip. Rev. Comput. Mol. Sci., vol. 1, no. 6, pp. 932942, Apr. 2011, doi: https://doi.org/10.1002/wcms.66.

[31]J. B. Young, "The condensation and evaporation of liquid droplets in a pure vapour at arbitrary Knudsen number," Int. J. Heat Mass Transf., vol. 34, no. 7, pp. 1649-1661, 1991, doi: https://doi.org/10.1016/00179310(91)90143-3.

[32]G. Gyarmathy, "The spherical droplet in gaseous carrier streams: review and synthesis," Multiph. Sci. Technol., vol. 1, no. 1-4, 1982, doi: https://doi.org/10.1615/MultScienTechn.v1.i1-4.20.

[33]Ø. Patursson et al., "Development of a porous media model with application to flow through and around a net panel," Ocean Eng., vol. 37, no. 2-3, pp. 314-324, 2010, doi: https://doi.org/10.1016/j.oceaneng.2009.10.001.

[34]T. Helsør and H. F. Svendsen, "Experimental characterization of pressure drop in dry demisters at low and elevated pressures," Chem. Eng. Res. Des., vol. 85, no. 3, pp. 377-385, 2007, doi: https://doi.org/10.1205/cherd06048.

[35]M. Souders and G. G. Brown, "Design of fractionating columns I. Entrainment and capacity," Ind. Eng. Chem., vol. 26, no. 1, pp. 98-103, 1934. 